\title{
Corrigendum
}

\section{Estimated dietary polyphenol intake and major food sources of the Brazilian population}

Renata A. Carnauba, Neuza M.A. Hassimotto and Franco M. Lajolo

(First published online 27th October)

DOI: https://doi.org/10.1017/S0007114520004237

In the original article, there was an incorrect statement about this study being the first to describe the intake of polyphenols by the Brazilian population. There was a previous analysis using data from National Dietary Survey 2008-2009 that was published in Revista de Nutrição (https://doi.org/10.1590/1415-52732015000200007). We apologize for this statement.

Reference

Carnauba RA, Hassimotto NMA and Lajolo FM (2020). Estimated dietary polyphenol intake and major food sources of the Brazilian population. British Journal of Nutrition, DOI: https://doi.org/10.1017/S0007114520004237 